\title{
Terminating links between emission trading programs
}

\author{
William A. Pizer ${ }^{\mathrm{a}, \mathrm{b}, \mathrm{c}, \mathrm{d}}$, Andrew J. Yates ${ }^{\mathrm{e}, *}$ \\ a Sanford School of Public Policy and Nicholas Institute for Environmental Policy Solutions, Duke University, United States \\ ${ }^{\mathrm{b}}$ Resources for the Future, United States \\ ${ }^{\mathrm{c}}$ National Bureau of Economic Research, United States \\ 'Center for Global Development, United States \\ e Department of Economics and Curriculum for the Environment and Ecology, University of North Carolina at Chapel Hill, United States
}

\section{A R T I C L E I N F O}

\section{Article history:}

Received 26 August 2014

Available online 28 March 2015

\section{JEL Classification:}

Q52

Q54

Q58

Keywords:

Emissions trading

Linking

Delinking

Speculation

\begin{abstract}
A B S T R A C T
Links between emission trading programs are not immutable, as highlighted by New Jersey's exit from the Regional Greenhouse Gas Initiative in 2011. This raises the question of what to do with existing permits that are banked for future use-choices that have consequences for market behavior in advance of, or upon speculation about, delinking. We consider two delinking policies. One differentiates banked permits by origin, the other treats banked permits the same. We describe the price behavior and relative costeffectiveness of each policy. Treating permits differently generally leads to higher costs, and may lead to price divergence, even with only speculation about delinking.
\end{abstract}

(c) 2015 Published by Elsevier Inc

\section{Introduction}

Despite significant effort and multiple rounds of negotiations, there is no coordinated global program to regulate carbon emissions. Rather than waiting for these efforts to bear fruit, various trans-national, national, and sub-national entities have developed independent, regional carbon-trading programs. Conceptually, each of these program features its own denomination of carbon permits and a registry in which permits are established, tracked, and ultimately canceled when surrendered for compliance purposes. Within this framework, some of these trading programs have decided to link together, meaning one program accepts another program's permits for compliance in its system and (typically) vice versa. For example, Quebec and California have chosen to link their programs, and the Regional Greenhouse Gas Initiative (RGGI) in the northeastern United States is effectively a system of linked state programs.

At the same time programs are choosing to link, we also have examples of delinking, in which the links between programs are severed. In May 2011, New Jersey announced it would delink from RGGI and terminate its program. More recently, in July 2014, Australia terminated its carbon pricing program even before an intended link with the EU Emissions Trading Scheme (ETS) had begun.

Termination of a compliance link, whether real or merely speculated by market participants, can have important consequences for the performance of the trading programs. In particular, when permits are being saved, or "banked," to meet future compliance obligations, current prices are strongly influenced by expected future prices, which in turn depend

\footnotetext{
* Corresponding author.

E-mail addresses: william.pizer@duke.edu (W.A. Pizer), ajyates@email.unc.edu (A.J. Yates).
} 
on beliefs about whether or not the programs will remain linked in the future. This possibility that mere speculation about delinking might influence market outcomes suggests that, at a minimum, when programs are initially linked, consideration should be given to the possibility of delinking in the future. In particular, do key choices about delinking and the handling of banked permits improve market outcomes when there is a real or speculative delink? Understanding the answer to such questions can then inform a decision about whether and how provisions for delinking might be included at the outset. To date, this issue has tended to be ignored if not outright avoided. ${ }^{1}$

To analyze this issue, we consider a two-period model with two regions. Firms in both regions face a regulation that requires them to surrender a tradable permit for each unit of pollution they emit. In the first period, the trading programs are linked; that is, firms in both regions can use permits issued by either region for compliance. First-period permits may also be banked for use in the second period. Turning to the second period, we first consider the fully linked baseline case in which the markets remained linked so firms can continue to use permits issued by either region. We then consider the issue of delinking, starting with certain termination of a link and then turning to the question of uncertainty and speculation. When markets are delinked in the second period, firms can only comply using second-period permits issued by their home region and-depending on the delinking rules-banked first-period permits from one or both regions. To complete the description of the delinked case, we must specify those rules. We consider two main policy options. In the asymmetric policy, saved permits are only valid to cover emissions in the region for which they were originally issued. In the symmetric policy, all saved permits are split such that a fraction $\pi$ are valid to cover emissions in one region and ( $1-\pi)$ are valid to cover emissions in the other region. A simple variant of the symmetric policy is one in which the market, rather than the regulator, chooses $\pi$. For either policy option, a firm in one region holding a permit, or fraction of a permit, that is valid only in the other region may sell those permits in the other region's market. We assume that these policies are announced when the link is formed, and in particular before the first-period trading begins.

Our main results show that different delinking policies can lead to significantly different market outcomes. Under asymmetric delinking, aggregate abatement costs can increase compared to the fully linked case and first-period prices of permits issued by each region can diverge. In contrast, under symmetric delinking, first-period prices never diverge and the number of cases in which abatement costs increase, and the magnitude of these increases, is smaller. Similar results hold when there is uncertainty or speculation about delinking, where speculation may involve an incorrect expectation about the likelihood of delinking. Here, we confirm that such speculation can affect cost-effectiveness and create price divergence. In addition, we show that symmetric delinking does a better job of reducing these consequences.

Some care must be taken with the interpretation of these results. In particular, we view them not as precise guidance for linked jurisdictions now contemplating a delink, but rather as advice to policymakers to consider delinking rules when a link is being created. In particular, speculation about delinking can have effects on market outcomes even if delinking never actually occurs, and the assumed form of delinking matters. By definition, our results provide insights about the market consequences of actual delinking, but it is less clear how to interpret our normative measure of cost-effectiveness in a real delinking scenario. The decision to terminate a link will likely be based on a variety of considerations beyond costeffectiveness, such as differences in ambition and/or desired carbon prices, which are outside the scope of our model. We do, however, consider different ways to treat banked permits when a link is terminated and other practical questions.

To put these ideas firmly into context, the next section briefly reviews the policy history and literature on linking and delinking. We then present our model and these main results in the section "A model of linking and delinking", including a numeric example. The section "Extension and discussion" presents additional considerations, including a flexible delinking policy, how the decision might be managed in real time, and the possibility that discussions about delinking may influence market expectations about its occurrence. The section "Conclusions" observes that speculation about policy changes more generally may have somewhat unique consequences for tradable permits versus other regulatory instruments. This may require more attention to potential adverse impacts and possibly influence our views about their relative performance.

\section{History and literature on linking}

During much of the 1990s, policy debate focused largely on how to design a single global market for trading carbon permits as "the" vehicle to address global climate change. A single global market would be an economically desirable outcome because one ton of a greenhouse gas emitted anywhere in the world has the same climate change consequences for everyone. Such a market would universally equalize the marginal cost of reducing emissions. A single market is also more resilient to regional disruptions, spreading any imbalance over a larger volume of supply and demand. The Kyoto Protocol was widely viewed as a first step in this direction.

However, a single global market has turned out to be a practical impossibility, at least for the time being. Participation in the Kyoto Protocol has declined to a largely symbolic gesture among countries with well-aligned domestic policies. Instead, we see a multiplicity of distinct regional, national, and even sub-national trading programs emerging. Most notably this includes the EU-ETS established in 2005, along with state-level programs established as part of RGGI in the United States,

\footnotetext{
${ }^{1}$ During an August 2012 press conference discussing the possibility of linking with the EU, Australian Minister Greg Combet repeatedly ducked questions about delinking or a "get-out" provision. See Combet (2012). The EU-ETS does not contain any provisions for the delinking of EU member or nonmember states (which, to date, only include countries in the broader European Economic Area and Switzerland). Both RGGI and the California-Quebec agreement specify a procedure for withdrawal, but do not specify what happens to banked permits.
} 
the New Zealand Emissions Trading Scheme, provincial trading programs in China, and programs in California and Quebec. Here, we view distinct trading programs as those with separate legal authorities establishing a compliance obligation for firms in a particular jurisdiction. ${ }^{2}$

Alongside the emergence of multiple trading programs, we have also witnessed a range of linkages among trading programs. By linkages, we mean the adoption of mechanisms by which permits from one trading program are recognized for compliance in another program and typically vice versa. At one extreme is RGGI, where participating states jointly developed their emission trading programs through negotiation of a model rule. The rule includes automatic recognition of other participating states' emission permits and was the basis of each state's legislation and/or regulation. At the other extreme is the proposed link between Australia and the EU-ETS. There, Australia began a process of harmonizing features with the EU-ETS in advance of linking (though this is now moot as Australia repealed its carbon regulation in July 2014). The link between California and Quebec begun in January 2014 lies somewhere in the middle-there was a great deal of cooperation as the individual programs were designed and implemented, but linking was not automatic.

There are already several examples of delinking (Ranson and Stavins, 2013). The first of these provides the clearest motivation for our analysis because it involves the severing of an active link between two capped permit markets. In May 2011, Governor Chris Christie announced that New Jersey would pull out of RGGI, effective at the end of 2011. At that point New Jersey would delink from the other states and end the compliance obligations for facilities in New Jersey. Almost immediately, the other states announced that they would continue to allow their regulated firms to make use of all current vintage (i.e., 2011 and earlier) New Jersey permits that were already in circulation. They later announced that firms could make use of all future vintage (i.e., 2012 and later) New Jersey permits that were already in circulation. ${ }^{3}$ New Jersey ultimately ended its emission trading program as announced.

The second example concerns the proposed link between the EU-ETS and Australia. Australia initiated a carbon tax in July 2012 that was intended to switch to an emissions trading program in July 2015. The intention to link to the EU-ETS was announced in August 2012, with a planned interim link in July 2015 (whereby Australian firms could use EU permits for compliance, but not vice versa) and a full bilateral link no later than July 2018. In November 2013, the new Australian government announced plans to eliminate their carbon cap-and-trade system, which would effectively terminate the link with the EU-ETS before it was even active. The government followed through on its announcement in July $2014 .{ }^{4}$ A final example of delinking also occurred in 2013, when the EU-ETS decided to no longer accept Clean Development Mechanism (CDM) credits from countries such as China and India. This is a slightly different example, as the CDM credit market does not represent a compliance market unto itself. The only demand for CDM credits comes from other programs that choose to link to the CDM.

\section{The literature on linking and delinking}

The delinking issue has not received much attention in the literature. Mehling and Haites (2009) note that linking agreements should require a procedure for terminating the link that addresses the status and validity of banked permits-a point ignored by the actual agreements to date. Ranson and Stavins (2013) document the three cases of delinking described above.

There is, however, an extant literature on linking. Mehling and Haites (2009) catalog existing links between trading programs and discuss potential future links. They also describe several different mechanisms by which links may be formed: unilateral, bilateral, and multiple (i.e., reciprocally adopted) unilateral. The differences between the last two are subtle and unimportant for our analysis. We assume that permits from one program can be used in the other program, and vice versa, which encompasses both the bilateral and multiple unilateral cases. Several papers consider the benefits and costs of linking, and the role that linking may play as a substitute for, complement of, or precursor to a potential international climate policy agreement (Jaffe et al., 2009; Flachsland et al., 2009; Ranson and Stavins, 2013). Tuerk et al. (2009) focus on barriers that may prevent links from forming. Finally, a series of papers looks at the details of forming specific links between countries in North America (Haites and Mehling, 2009), between EU and USA (Sterk and Kruger, 2009), between Australia and the EU (Jotzo and Betz, 2009), and the particular problem of international aviation and shipping emissions (Haites, 2009).

\section{To link or not to link?}

An accounting of the costs and benefits of forming a link naturally starts with the costs associated with abating pollution. As described by Jaffe et al. (2009), there are three mechanisms by which linking will lower aggregate abatement costs. First, immediate cost-effectiveness savings are realized by two regions that choose to link: the initially low-price region sells permits at prices above their local cost; the initially high-price region replaces high-cost local abatement with cheaper

\footnotetext{
${ }^{2}$ For example, the EU-ETS was established in all EU Member States by a single directive of the European Council. In contrast, RGGI was established by separate statutory and/or regulatory authority in each participating state.

${ }^{3}$ The RGGI design arranged for each auction to sell a combination of current and future vintage permits from each participating state. See various documents at http://www.rggi.org/design/history/njparticipation.

${ }^{4}$ See http://www.aph.gov.au/About_Parliament/Parliamentary_Departments/Parliamentary_Library/pubs/rp/rp1314/ClimateChangeTimeline.
} 
imported permits. Second, and regardless of any initial or expected price differences, both regions will also tend to experience reduced volatility. Local shocks to permit demand-particularly weather and business cycles-lead prices to diverge from their expected value. Under very basic assumptions, it is easy to show that volatility raises compliance costs. ${ }^{5}$ By linking systems, however, volatility should decline as local shocks are spread over a larger market. Third, increased liquidity-particularly for a small region linking to a large one-can reduce transaction costs by increasing access to derivatives and other hedging tools as well as reducing bid-ask spreads. ${ }^{6}$

While the focus of the economic literature tends to be cost-effectiveness, it is useful to recognize the wider variety of reasons that may affect a jurisdiction's decision about linking and potentially delinking. On the "pro-linking" side, in addition to reduced volatility and increased liquidity, political strengthening may be lurking behind the enthusiasm of some linking proponents. This reflects the idea that the more linked and integrated a particular ETS becomes, the more resilient it becomes to weakening or dismantling in the future. ${ }^{7}$ The flip side of this view is that delinking may be seen as a precursor to dismantling-as it was in the case of New Jersey.

The greatest obstacle to linking tends to be the need to harmonize programs in advance of linking. Often, differences in market design reflect different preferences that may be hard to reconcile. California, for example, has a price floor that limits low prices along with a system of permit reserves that attempts to manage the risk of high prices. The EU has no automatic mechanism tied to prices and might find such features unpalatable. ${ }^{8}$ Fully integrating the markets, however, would expose the European market to those features. In many ETSs, choices about such features have been critical to achieving an internal political agreement, making subsequent adjustments difficult.

Related to this, linking to another program means accepting current and future choices by that other jurisdiction about its future ambition toward decreasing carbon emissions. 9 This has interesting consequences, potentially pitting the economic gains from integration against broader equity concerns. On the one hand, the largest economic benefit comes from integrating a high-price market with a low-price market. On the other hand, large price discrepancies among jurisdictions might easily raise red flags about the potential acceptability of each other's ambition among countries with similar economic status. That is, while economic benefits from linking are shared by both parties, they rest on top of the prior-to-linking costs imposed by each jurisdiction unilaterally. Linking means, for a high-price market especially, accepting what is (or what appears to be) lower ambition in a low-price market. This may not be politically acceptable in the highprice region and, ultimately, could adversely affect choices about future ambition in other, yet-unregulated jurisdictions by suggesting that lower ambition is acceptable.

Finally, regardless of concerns about ambition, different jurisdictions may simply prefer different prices, reflecting different views about the social cost of carbon, the potential for dynamic efficiency gains, and domestic distributional consequences. A jurisdiction may view a high price as desirable, for example, because carbon pricing is also a powerful tool to drive a domestic agenda, such as changing the structure of a coal-based economy to a low carbon economy, moving toward broader sustainability goals, addressing local pollution, raising revenues, or stimulating new investment. This might include the potential to achieve innovation spillovers or avoid carbon lock-in. Market integration that lowers $\mathrm{CO}_{2}$ prices may achieve near-term cost savings with regard to climate change mitigation, but reduce progress toward other goals as well as create higher longer-term mitigation costs if higher prices are ultimately justified (by the social cost of carbon and/or dynamic efficiency gains). Or a jurisdiction might feel that high market prices have unpalatable and unavoidable distributional consequences-across regions, income classes, or other dimensions-and prefer lower market prices in concert with other regulations and technology incentives to achieve its carbon mitigation goals. While market integration and higher prices from selling permits abroad could generate net benefits for the jurisdiction as a whole, the withinjurisdiction distributional effects of higher prices may be undesirable.

In this paper, we start with a focus on the cost-effectiveness criterion, and then subsequently consider how policy might be designed to account for some of these broader issues. We will also identify an additional issue, price divergence, that may occur in advance of delinking and create other pecuniary and non-pecuniary costs.

\section{A model of linking and delinking}

Consider a two-period, two-region model in which firms generate pollution and regional governments use emission trading programs to limit the aggregate levels of emissions. The government in each region creates an endowment of permits for each period, $w_{r t}>0$, leading to four ( 2 regions $\times 2$ time periods) denominations of permits. The subscripts

\footnotetext{
${ }^{5}$ Imagine $C(\bar{q}-q)$ is the cost of reducing emissions from $\bar{q}$ to $q$, where $q$ is an emission cap and $\bar{q}$ is the uncontrolled emission level. If $\bar{q}$ is uncertain and costs are a convex function of emission reductions, Jensen's inequality states that $E[C(\bar{q}-q)]>C(E[\bar{q}]-q)$. That is, increased uncertainty about $\bar{q}$ raises costs.

${ }^{6}$ In addition, linking a small region to a large one may reduce the ability of firms to exert market power.

7 This is analogous to the idea that a free trade agreement can lock in market reforms. See Hufbauer and Schott (2005).

8 In 2014, the EU ETS began a process to adopt a "Market Stability Reserve" that can add and remove permits from the ETS based on the quantity-based measures of over- or under-supply, rather than observed prices. The effectiveness of this mechanism is still unclear (Arvanitakis, 2014).

${ }^{9}$ See Helm (2003) for an analysis of this issue.
} 
$r \in\{H, L\}$ and $t \in\{1,2\}$ indicate region and period, respectively. ${ }^{10}$ Firms that emit pollution are required to surrender one permit for each ton of emissions. Let $e_{r t}$ denote the aggregate emissions in region $r$ and period $t$. For any of the policies we consider, it is always acceptable to surrender a permit denominated by the region where and period when the emission occurs. If these policies made no further provisions for trade, then the permit markets would be characterized by the simple constraints that $e_{r t}=w_{r t}$ for all $r$ and $t$.

More generally, we consider policies that allow permits to be used for compliance beyond their denominated period or region. We say a policy allows banking when a permit from one period can be saved for a future period, and we say a policy allows linking when a permit from one region can be used in another region. Banking and linking allow flexibility to shift emissions between regions and time periods. Letting $B_{r}$ represent the portion of region r's period-one endowment saved for use in period 2 (banking), and $\Delta_{t}$ represent the use of region $L$ permits for compliance in region $H$ in period $t$ (linking), we can write the more general market constraints as

$$
\begin{aligned}
& e_{H 1}=w_{H 1}+\Delta_{1}-B_{H} \\
& e_{L 1}=w_{L 1}-\Delta_{1}-B_{L} \\
& e_{H 2}=w_{H 2}+\Delta_{2}+B_{H} \\
& e_{L 2}=w_{L 2}-\Delta_{2}+B_{L} .
\end{aligned}
$$

These constraints encompass the demand and supply for permits in each region and period. For example, for period 1 in region $H$, emissions are equal to the permit endowment, plus the influx of permits from region $L$, minus any banking for period 2. Without loss of generality, we assume that $\Delta_{1}$ is positive; that is, $H$ is the high-price region prior to linking in period one and $L$ is the low-price region (if not, simply relabel the regions).

To properly integrate banking policy into the model, we need to supplement (1) with two additional sets of constraints. The first allows earlier vintage permits to be surrendered in later periods but not the other way around. This implies

$$
B_{r} \geq 0 \text {, }
$$

which we refer to as the "no borrowing" constraints. ${ }^{11}$ Second, we have defined banking in region $r$ to be the portion of region $r$ 's endowment saved from period 1 for use in period 2, which implies the constraints $B_{r} \leq w_{r 1}$. Absent these upper bounds on banking, the mathematical model does nothing to avoid permits from one jurisdiction in period 1 being used for compliance in another jurisdiction in period 2 via linking in period 1 and then banking, regardless of whether $\Delta_{2}$ is constrained to zero. In our discussions of delinking, we will explore particular rules that might allow such opportunities. But that requires these preliminary definitions that carefully disentangle the consequences of, and interactions between, banking and linking.

It is convenient to replace the constraints $B_{r} \leq w_{r 1}$ with the equivalent constraints $-e_{L 1} \leq \Delta_{1} \leq e_{H 1}$. The equivalence follows from the first two equations in (1). The convenience occurs when we interpret Lagrange multipliers as market prices. ${ }^{12}$ Under our assumption that $\Delta_{1}$ is positive, $-\Delta_{1} \leq e_{L 1}$ is always satisfied. Thus we are left with

$$
\Delta_{1} \leq e_{H 1},
$$

which we call the "maximum link" constraint, because it describes a limit on the amount of permits transferred from region $\mathrm{L}$ to region $\mathrm{H}$.

It is useful to characterize the market equilibrium with an optimization problem. Accordingly, consider a representative agent seeking to minimize the sum of aggregate abatement costs across regions and time subject to the market and policy implementation constraints. Region and time-specific aggregate abatement cost functions $C_{r t}\left(e_{r t}\right)$ are defined with respect to aggregate emissions of pollution $e_{r t}$ and satisfy standard assumptions. ${ }^{13}$ (We refer to $-C_{r t}^{\prime}$ as marginal abatement costs, or MAC for short.) This leads to a general problem,

$$
\begin{aligned}
& \min _{e_{r t}, \Delta_{t}, B_{r}} \sum_{r \in\{H, L\} t} \sum_{\text {such that }} F\left(e_{r t}, w_{r t}, \Delta_{r t}\left(e_{r t}\right), B_{r}\right), \\
& \text { such }
\end{aligned}
$$

where $F$ represents the market and policy implementation constraints (1-3) or variants associated with delinking as described below. ${ }^{14}$ Under our assumptions about abatement costs, a competitive market equilibrium with many firms is

\footnotetext{
${ }^{10}$ As discussed in more detail below, the labels $H$ and $L$ signify that one region can be viewed, without loss of generality, as a high-cost region and the other as a low-cost region.

${ }^{11}$ Some programs have allowed a limited amount of borrowing, which would create an alternate constraint $B_{r} \geq-\bar{B}_{r}$, where $\bar{B}_{r}$ is the borrowing limit in region $r$. This does not affect our basic results, as discussed in Appendix B.

${ }^{12}$ Under the maximum link constraint, the Lagrange multiplier on the market constraint will correspond to the market price because this constraint is the only place in the Lagrangian where the endowment occurs. Under the constraint on banking, the market price will equal the multiplier on the market constraint plus the multiplier on the banking constraint. In either case, the market price reflects the change in cost from one additional unit of endowment.

${ }^{13}$ Formally we assume that the abatement cost functions are twice-differentiable, convex, $C_{r t}^{\prime}<0$, and $\lim _{e_{r t} \rightarrow 0} C_{r t}\left(e_{r t}\right) \rightarrow \infty$. The last assumption rules out the possibility that $e_{r t} \leq 0$. Furthermore, from (1), it also implies that it will never be optimal to bank all of the permits from both regions in period 1 (i. e. $\left.B_{H}+B_{L}<w_{H 1}+w_{L 1}\right)$. We also assume that permit endowments are such that the prices for all denominations of permits are strictly positive, which justifies using equality signs in the market constraints (1).

${ }^{14}$ For simplicity we assume the discount factor is one.
} 
equivalent to the solution to the optimization problem (4) with the equilibrium permit prices equal to the Lagrange multipliers on the appropriate equations in $F^{15}$

We now turn to the analysis of the effects of various delinking policies on aggregate costs and market prices. Our ultimate goal is to understand these effects when there is uncertainty and speculation about whether or not the markets will remain linked in the second period. As a preliminary step, however, it is useful to assume at first there is no uncertainty about the second period. Using this framework, we analyze three different policies: no delinking, asymmetric delinking, and symmetric delinking. We then consider the effect of uncertainty and speculation.

\section{No delinking-first best}

Under the no delinking policy, markets are linked in both the first and second period. This scenario is the first-best because all other policy scenarios will lead to, at best, aggregate abatement costs equal to those in this scenario.

Consider maximizing the objective function (4) subject to the market and policy implementation constraints described by (1-3). We characterize the solution to this problem with the first-order conditions. Let $p_{r t}$ be the Lagrange multiplier on the region $r$ and period $t$ market equilibrium constraint (which, as noted, are also the market prices), $\lambda_{r}$ the Lagrange multiplier on the region $r$ no-borrowing constraint, and $\gamma$ the Lagrange multiplier on the maximum link constraint. Then the first-order conditions can be written as

$$
\begin{aligned}
& \text { FOC for } \left.e_{r t}: \quad-C_{r t}^{\prime}\left(e_{r t}^{\ell *}\right)=p_{r t}^{\ell *} \quad \text { (MAC equals price in region } r \text { and time } t\right) \\
& \text { FOC for } \Delta_{t}: \quad p_{H t}^{\ell *}=p_{L t}^{\ell *} \equiv p_{t}^{\ell *} \quad \text { (Linking equates } H \text { and } L \text { prices each period) } \\
& \text { FOC for } B_{r}: \lambda_{r}^{\ell *}=p_{r 1}^{\ell *}-p_{r 2}^{\ell *} \equiv p_{1}^{\ell *}-p_{2}^{\ell *} \equiv \lambda^{\ell *} \quad \text { (Rubin-Schennach banking equation), }
\end{aligned}
$$

where we have used the superscript $\ell^{*}$ to indicate the solution to the no-delinking problem.

Because the markets are linked in both periods, the solution collapses to the standard result for a single permit market with banking (Rubin, 1996; Schennach, 2000). There is a single price in both regions, and that price is either (a) the same across periods or (b) falling from period 1 to 2. If prices (e.g., marginal costs) at a candidate equilibrium are higher in period 2 , costs can be reduced by lowering emissions in period 1, banking more permits, and emitting more in period 2 . This will continue until prices are equalized. If prices are higher in period 1 , costs can be reduced by lowering emissions in period 2 , banking fewer permits, and emitting more in period 1. This will continue until either prices are equalized or the no borrowing constraint is binding. Thus, when there is a price difference between the two periods, the discrepancy $\lambda_{r}^{\ell *}=\lambda^{\ell *}=p_{1}^{\ell *}-p_{2}^{\ell *}$ reflects the hypothetical cost savings from shifting one more ton of emissions from second period to the first, if it were allowed.

Notice that the maximum link constraint is not binding and $\gamma^{\ell *}=0$, so it does not appear in the first-order conditions. ${ }^{16}$ There is no pressure to move $L$ permits to second-period region $H$ through linking and banking in period 1 because markets are linked in the second period. One can directly move permits from $L$ to $H$ in the second period instead.

A final point is that, provided $B_{r}^{\ell *}>0$, the solution to the optimization problem is not unique in terms of $\Delta_{t}$ and $B_{r}$. For a given solution, we can always choose $B_{H}^{\ell *}+\epsilon, B_{L}^{\ell *}-\epsilon, \Delta_{1}^{\ell *}+\epsilon$ and $\Delta_{2}^{\ell *}-\epsilon$ for any small value of $|\epsilon|$, and this will also be a solution with the same $e_{r t}^{\ell *}$ and $p_{r t}^{\ell *}$. This suggests that linking in the second period may be unnecessary to generate equal second-period prices. Suppose we pick a not-so-small $\epsilon=\Delta_{2}^{\ell *}$ for a given solution. This could potentially move us to an equivalent solution with the same emission and prices, but no region-to-region trading in period 2 . The question is whether, in moving to this new solution, either the maximum link constraint (3) or the no-borrowing constraint (2) is reached. If so, it will not be possible to delink in the second period and achieve the same outcome as in the no-delinking case through this particular model. To elaborate these conditions, we now turn to the discussion of delinking.

\section{Asymmetric delinking}

In our delinking cases, the permit markets are linked in the first period but not in the second. We need not be concerned at this point about why this occurs, because we simply want to study the effects of delinking on prices and abatement costs. To close the model, we need to specify how permits that are banked at the end of period 1 are treated. We refer to the first policy we consider as asymmetric delinking. This is perhaps the most natural "default" policy that would govern delinked markets. Here banked region $H$ permits are only valid in region $H$ and banked region $L$ permits are only valid in region $L{ }^{17}$ If a firm in one region is holding any permits banked from the other region, they may sell these permits in the other region's market.

\footnotetext{
${ }^{15}$ See Cronshaw and Kruse (1996).

${ }^{16}$ Suppose that $\gamma^{\ell *}>0$. Then $p_{H 1}^{\ell *}$ would be replaced by $p_{H 1}^{\ell *}-\gamma^{\ell *}$ in the FOCs for $e_{H 1}$ and $\Delta_{1}$. Then, $p_{H 1}^{\ell *}>p_{L 1}^{\ell *}$ and $e_{H 1}^{\ell *}=\Delta_{1}^{\ell *}$; the latter implies $B_{H}^{\ell *}=w_{H 1}^{\ell *}>0$ based on (1). But if $B_{H}^{\ell *}>0$, then $\lambda_{H}^{\ell *}=0$ and $p_{H 1}^{\ell *}=p_{H 2}^{\ell *}$. From the FOC on $\Delta_{2}^{\ell *}$, we know $p_{H 2}^{\ell *}=p_{L 2}^{\ell *}$. Thus we have $p_{L 1}^{\ell *}<p_{L 2}^{\ell *}$. This contradicts the non-negativity constraint that $\lambda_{L} \geq 0$; therefore, $\gamma^{\ell *} \ngtr 0$.

17 It has not escaped our notice that the RGGI delinking did not involve this policy. Governor Christie's announcement was accompanied by an almost immediate announcement by the RGGI authority that symmetric delinking would occur, which we discuss next. However, the decision to make an explicit announcement suggests that RGGI authorities may well have worried that absent such an announcement, market participants would have assumed asymmetric treatment.
} 
Under this policy, the market and policy implementation constraints are

$$
\begin{aligned}
& e_{H 1}=w_{H 1}+\Delta_{1}-B_{H} \\
& e_{L 1}=w_{L 1}-\Delta_{1}-B_{L} \\
& e_{H 2}=w_{H 2}+B_{H} \\
& e_{L 2}=w_{L 2}+B_{L} \\
& B_{r} \geq 0 \\
& \Delta_{1} \leq e_{H 1}
\end{aligned}
$$

Because markets are not linked in the second period, $\Delta_{2}$ is constrained to be zero and has been dropped from the equations; otherwise (5) is the same as (1-3). As we previously noted and shall now see, this restriction does not necessarily mean that second period prices cannot be equalized-in some cases, the remaining three flexibility variables, $B_{H}, B_{L}$, and $\Delta_{1}$, can be sufficient. Maximizing the objective function (4) subject to (5) gives the first-order conditions:

$$
\begin{aligned}
& \text { FOC for } e_{r t \neq H 1}: \quad-C_{r t}^{\prime}\left(e_{r t}^{a *}\right)=p_{r t}^{a *} \quad(\text { MAC equals price except maybe } H 1) \\
& \text { FOC for } e_{H 1}: \quad-C_{H 1}^{\prime}\left(e_{H 1}^{a *}\right)=p_{H 1}^{a *}-\gamma^{a *} \\
& \text { FOC for } \Delta_{1}: \quad p_{H 1}^{a *}-\gamma^{a *}=p_{L 1}^{a *} \quad \text { (Linking equates } H \text { and } L \text { MAC in period } 1 \text { but perhaps not prices) } \\
& \text { FOC for } B_{r}: \quad \lambda_{r}^{a *}=p_{r 1}^{a *}-p_{r 2}^{a *} \quad \text { (Rubin-Schennach banking equation), }
\end{aligned}
$$

where the superscript $a^{*}$ indicates the solution to the asymmetric delinking problem. These look similar to the first-order conditions for the no-delinking case, with two exceptions. First, the Lagrange multiplier on the maximum link constraint $\gamma^{a *}$ may be positive, and correspondingly it appears in the first-order condition for $e_{H 1}$ and $\Delta_{1}$. Second, there is no longer an FOC for $\Delta_{2}$ equating regional prices in period 2 , because $\Delta_{2}$ is constrained to be zero.

An examination of these exceptions reveals that asymmetric delinking is characterized by two salient features: Prices in the first period may diverge and aggregate abatement costs may be higher than first-best. We now analyze these features in turn. Suppose that $\gamma^{a *}$ is positive. Then it follows from the first-order condition for $\Delta_{1}$ that first-period prices are not the same. But, combining the first-order conditions, it follows that $-C_{L 1}^{\prime}=-C_{H 1}^{\prime}$, so the first-period marginal abatement costs are the same, and they are equal to $p_{L 1}^{a *}$. We see that prices diverge in period 1, but marginal costs do not. To understand both when this may occur and why prices diverge, return for the moment to the first-best outcome with no delinking and suppose that abatement costs and permit endowments are such that, in equilibrium, period 2 emissions by region $H$ exceeds the volume of all region $H$ permits (e.g., $e_{H 2}^{\ell *}>w_{H 1}+w_{H 2}$ ). In this case, banking alone will not allow this level of emissions; linking in period 2 is a necessary part of the first-best equilibrium. What happens when the same costs and permit endowments now arise under a policy of asymmetric delinking? The unquenchable demand for $H$ permits in period 2 drives up $p_{H 2}$ and leads firms to bank all of the region $H$ permits in period 1 . Compliance in period 1 is then achieved entirely using $L$ permits in both regions, so marginal abatement costs in both regions are equal to the price of $L$ permits. Firms would like to bank even more permits in region $H$, using region $L$ permits in addition to all of the region $H$ permits. At the margin, such movement would yield a profit of $\gamma^{a *}$-but that would violate the maximum link constraint.

Turning now to a comparison of the aggregate abatement costs of the asymmetric delinking policy to first-best, we ask two questions. First, are the first-best emission levels in period $2, e_{r 2}^{\ell *}$, more than the period 2 endowment $w_{r 2}$ in both regions? If the answer is no, then second-period linking is necessary to lower emissions in one region to reach the first-best. Banking alone cannot do this, and hence asymmetric delinking is more costly. If yes, we turn to a second question: are the first-best emission levels in period $2, e_{r 2}^{\ell *}$, less than the total endowment in each region, $w_{r 1}+w_{r 2}$, particularly in region $H$ ? If yes, the first-best outcome in terms of emissions and prices is achieved even with asymmetric delinking. If not, the maximum link constraint will bind and the outcome will not be first-best.

We can summarize these outcomes with three cases:

Case $1: w_{r 2}>e_{r 2}^{\ell *}$ for one region. ${ }^{18}$ In this case, to obtain the first-best outcome we must move permits out of this region in the second period and lower emissions below the endowment. This cannot be done with banking alone, which only serves to increase second-period permit supply. So the asymmetric delinking outcome has higher costs than the first-best outcome.

Case 2: $w_{r 2}<e_{r 2}^{\ell *}$ for both regions, and $w_{H 2}+w_{H 1}<e_{H 2}^{\ell *}$. Here, to obtain the first-best outcome, we want to move permits into both regions in period 2. At first blush, it may seem that we can do this under asymmetric delinking-we just bank the necessary volume of permits in each region. However, permit demand in the second period for region $H$ is such that, even when all of the region $H$ permits from both periods are used in period 2, it is not enough to reach the no-delinking outcome. Some region $L$ permits need to be used for compliance in second-period region $H$, which is constrained with respect to second-period $L$ permits by delinking generally $\left(\Delta_{2}=0\right)$ and with respect to first-period $L$ permits by the rules of asymmetric delinking (stipulating banked $L$ permits cannot be used in region $H$ ). It follows that asymmetric delinking cannot obtain the first-best outcome and hence has higher costs than first-best.

\footnotetext{
18 Note this can never be true for both regions. Total emissions in the second period $\left(e_{H 2}+e_{L 2}\right)$ cannot exceed total permits in the second period $\left(w_{2 H}+B_{H}+w_{2 L}+B_{L}\right)$. Given borrowing is not allowed, total second-period permits are no less than second-period endowment ( $\left.w_{H 2}+w_{L 2}\right)$. This logic would be contradicted if second-period emissions in both regions were less than second-period endowment in both regions.
} 
Case 3: $w_{r 2}<e_{r 2}^{\ell *}$ for both regions, and $w_{H 2}+w_{H 1}>e_{H 2}^{\ell *}$. Again, to obtain the first-best outcome we want to move permits into both regions in period 2 . In this case, there are enough region $H$ permits to reach the first-best equilibrium and the asymmetric delinking outcome has the same costs as that equilibrium.

It is useful to summarize these results formally.

Proposition 1. If either Case 1 or Case 2 holds, then the outcome under asymmetric delinking has higher costs than the first-best outcome. If Case 3 holds, then the outcome under asymmetric delinking achieves the first-best outcome.

In Cases 1 and 2, the asymmetric delinking outcome has higher aggregate abatement costs than the first-best outcome. The exact mechanism by which these higher costs occur, however, is different. In Case 2, the higher costs arise only from the need to bank more permits into one of the regions than the maximum link constraint allows. This contrasts with Case 1 , where the higher costs arise from the inability to borrow permits from a second-period region with low marginal costs, which the no-borrowing constraint does not allow, perhaps in conjunction with a binding maximum link constraint. ${ }^{19}$

What are the implications of the price divergence and higher abatement costs associated with asymmetric delinking? Although some degree of higher abatement costs may be inevitable when programs are delinked, we might ask whether other delinking policies might do better. As for price divergence, it may have several consequences. Transaction costs may increase as all firms in both regions will want to use permits from the lower-price region for compliance, which creates larger transaction volumes. ${ }^{20}$ Moreover, government officials may not like the idea that permits from one region are essentially flooding the other region's market. Taken together, these points suggest a need for other delinking policies that avoid price divergence and lower aggregate abatement costs. With that in mind, we turn to our idea for symmetric delinking.

\section{Symmetric delinking}

Instead of each region's banked permits reverting to their region of origin in the event of a delink, suppose we define a rule for distributing the total quantity of banked permits $B_{H}+B_{L}$. In particular, we specify that region $H$ gets $\pi\left(B_{H}+B_{L}\right)$ permits and region $L$ gets $(1-\pi)\left(B_{H}+B_{L}\right)$ permits, where $0 \leq \pi \leq 1$. This could be implemented by splitting each banked permit, regardless of origin, into a fraction $\pi$ of a second-period $H$ permit and a fraction $(1-\pi)$ of a second-period $L$ permit. Firms in, say, region $H$ would be able to sell the fraction $(1-\pi)$ in the $L$ market, but these permits could not be used for compliance in region $H$. Under this rule, it does not matter whether permits are banked in region $L$ or $H$; they are treated symmetrically. And, by specifying that the total emissions available in period 2 equals $\pi\left(B_{H}+B_{L}\right)+(1-\pi)\left(B_{H}+B_{L}\right)=B_{H}+B_{L}$, we preserve the aggregate emission level across time and region. ${ }^{21}$

Under these provisions, the market and policy implementation constraints become

$$
\begin{aligned}
& e_{H 1}=w_{H 1}+\Delta_{1}-B_{H} \\
& e_{L 1}=w_{L 1}-\Delta_{1}-B_{L} \\
& e_{H 2}=w_{H 2}+\pi\left(B_{H}+B_{L}\right) \\
& e_{L 2}=w_{L 2}+(1-\pi)\left(B_{H}+B_{L}\right) \\
& B_{r} \geq 0 \\
& \Delta_{1} \leq e_{H 1}
\end{aligned}
$$

These are the same as asymmetric delinking, except the volume of banked permits in period 2 has been replaced by the new rule for splitting banked permits.

The corresponding first-order conditions are

$$
\begin{array}{ll}
\text { FOC for } e_{r t}: & -C_{r t}^{\prime}\left(e_{r t}^{s *}\right)=p_{r t}^{s *} \quad \text { (MAC equals price) } \\
\text { FOC for } \Delta_{1}: & p_{H 1}^{S *}=p_{L 1}^{s *} \equiv p_{1}^{s *} \quad(\text { Linking equates } H \text { and } L \text { prices in period } 1) \\
\text { FOC for } B_{r}: & \lambda_{r}^{s *}=p_{r 1}^{s *}-\pi p_{H 2}^{s *}-(1-\pi) p_{L 2}^{s *} \equiv \lambda^{s *} \quad \text { (Banking under symmetric delinking), }
\end{array}
$$

where the superscript $s^{*}$ indicates the solution to the symmetric delinking problem. As with the no-delinking policy, the maximum link is not binding and $\gamma^{s *}=0 .{ }^{22}$ In other words, it is unnecessary to try to use region $L$ permits for banking in region $H$, which previously led to a binding constraint. Under symmetric delinking, banking region $L$ permits in region $L$

\footnotetext{
${ }^{19}$ Note that in Case 2, the Lagrange Multiplier $\gamma^{a *}$ is always positive. In Case $1, \gamma^{a *}$ may or may not be positive, but $\lambda_{r}^{a *}$ is always positive for one (or both) regions. Most emission trading programs to date have encouraged considerable banking, making Case 1 seem less likely in practice. That is, with smaller, "stricter" endowments in the future, $e_{r 2}^{\ell *}>w_{r 2}$ and banking rather than borrowing is the norm. The EU-ETS, for example, currently holds a bank equal to roughly one year's worth of compliance needs.

20 Joas and Flachsland (2014) argue that transaction costs are quite low based on evidence from the EU and US. However, a situation where a large volume of allowances must change hands in response to delinking is different from the cases they have studied and perhaps result in higher transaction costs.

21 When New Jersey delinked, RGGI announced that all circulating permits would be valid in the remaining RGGI states. Because New Jersey also cancelled its CO2 program, this implied a value of $\pi=1$ (assuming New Jersey is region $L$ ).

${ }^{22}$ If $\gamma^{S *}>0$ then $p_{H 1}^{s *}$ would be replaced by $p_{H 1}^{S *}-\gamma^{s *}$ in the FOCs for $e_{H 1}$ and $\Delta_{1}$ and we know $e_{H 1}^{S *}=\Delta_{1}^{s *}$. This implies $B_{H}^{S *}=w_{H 1}>0$ based on (7). But if $B_{H}^{s *}>0$, then $\lambda_{H}^{s *}=0$ and $p_{H 1}^{s *}=\pi p_{H 2}^{s *}+(1-\pi) p_{L 2}^{s *}$. With $\lambda_{L}^{s *} \geq 0$, we have $p_{L 1}^{s *} \geq \pi p_{H 2}^{s *}+(1-\pi) p_{L 2}^{s *}$, or $p_{L 1}^{s *} \geq p_{H 1}^{s *}$. But this implies $\gamma^{s *} \leq 0$, which contradicts the premise that $\gamma^{s *}>0$. Therefore, $\gamma^{s *} \ngtr 0$.
} 
accomplishes exactly the same thing. Because $\gamma^{s *}=0$, first-period prices are equated. Thus, symmetric delinking automatically addresses one concern with asymmetric delinking, that first-period prices might diverge.

What about the second concern with asymmetric delinking, that it raises abatement costs relative to no delinking, perhaps more than is necessary? With symmetric delinking, we have an additional parameter $\pi$, which suggests that by carefully picking its value we may be able to do better than asymmetric delinking. The following proposition makes this observation precise.

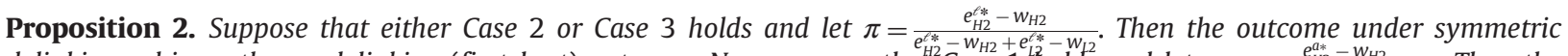

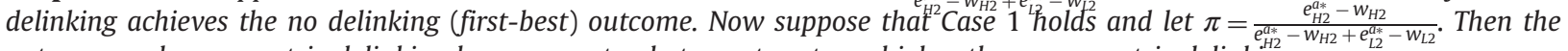
outcome under symmetric delinking has aggregate abatement costs no higher than asymmetric delinking.

Note that $e_{r 2}-w_{r 2}$ is the volume of banked permits necessary in each region to achieve a particular outcome when the programs are delinked in the second period. Therefore, the basic intuition is that we pick $\pi$ to divide the pool of banked permits $B_{H}+B_{L}$ in such a way that matches the necessary division in the desired outcome. That desired outcome is either the asymmetric outcome or, so long as $e_{r 2}^{\ell *} \geq w_{r 2}$, the no delinking outcome. Setting $\pi$ this way makes desired outcome feasible under symmetric delinking; further cost minimization can do no worse.

We verify Proposition 2 by constructive proofs. Consider Case 1 first. Comparing the constraint sets (7) and (5), symmetric banking can match the asymmetric equilibrium if $\pi\left(B_{H}^{a *}+B_{L}^{a *}\right)=B_{H}^{a *}$ where $B_{r}^{a *}=e_{r 2}^{a *}-w_{r 2}$. Solving for $\pi$ gives the expression in the Proposition. Now consider Cases 2 and 3, when $w_{r 2} \leq e_{r 2}^{\ell *}$ for both regions. Comparing the constraint sets (7) and (1-3) we can now match the no delinking equilibrium if $\pi\left(B_{H}^{\ell *}+B_{L}^{\ell *}\right)=e_{H 2}^{\ell *}-w_{H 2}$. Solving for $\pi$ and noting that $B_{H}^{\ell * *}+B_{L}^{\ell *}=e_{H 2}^{\ell *}-w_{H 2}+e_{L 2}^{\ell *}-w_{L 2}$ gives the expression in the Proposition. (Note that the condition for Cases 2 and $3, w_{r 2} \leq e_{r 2}^{\ell *}$, ensures $1 \geq \pi \geq 0$.)

Proposition 2 shows that symmetric delinking with a particular choice of $\pi$ obtains the first-best in Case 2 as well as Case 3. This is in contrast to asymmetric delinking, which obtains the first-best only in Case 3 . In addition, for Case 1, there is a choice of $\pi$ where abatement costs under delinking are no higher than under asymmetric delinking. The intuition for these results is as follows. Given the condition $w_{r 2} \leq e_{r 2}^{\ell *}$ (associated with Cases 2 and 3), the first-best solution requires permits to flow into both regions in period 2 and the borrowing constraint is not relevant to reach that outcome. The problem for asymmetric linking is that the total region $H$ permit supply in period 2 is limited to the total region $H$ endowment, $w_{H 1}+w_{H 2}$, which may be less than is necessary for the first-best (e.g., Case 2). Symmetric linking with a particularly large $\pi$ surpasses this constraint: The fraction/number of banked permits arriving in region $H$ can exceed the fraction/number of banked permits originating in region $H$. Given $w_{r 2}>e_{r 2}^{\ell *}$ for one region (associated with Case 1), however, the first-best solution requires permits to flow out of one region in period 2. This cannot be done with either asymmetric or symmetric delinking. But symmetric delinking can at least mimic the outcome of asymmetric delinking in this case.

These results show that, compared to the asymmetric model, symmetric delinking can sometimes improve costs while never worsening them-so long as $\pi$ is chosen well. We now consider a variant of the symmetric delinking model that ensures this is the case.

\section{Simpler symmetric delinking}

Suppose that instead of the regional governments choosing how to divide banked permits between regions in period 2 , firms were simply free to use banked permits in either region regardless of their origin. This might be viewed as a "simpler" symmetric delinking policy. Ultimately, the market would choose some fraction of banked permits $\pi$ to use in region $H$, while using the other fraction $(1-\pi)$ in region $L$. In this way, the market and implementation constraints are again given by (7), but now $\pi$ is a choice variable in the optimization problem (for completeness, we should also add the constraints $\pi \leq 1$ and $-\pi \leq 0$ ). The cost minimizing choice of $\pi$ must lead to costs at least as low as the $\pi$ specified in Proposition $2 .^{23}$ Therefore simpler symmetric delinking will always either achieve the first-best outcome or achieve costs no higher than asymmetric delinking. ${ }^{24}$

\section{Uncertainty about delinking}

Our results so far show that, when market participants know for certain whether or not the markets will be linked in the second period and act accordingly, asymmetric delinking raises abatement costs in more cases and to a higher degree than

\footnotetext{
${ }^{23}$ It is straightforward to see that the additional FOC with respect to $\pi$ will be $p_{L 2}^{s *}-p_{H 2}^{s *} \leq 0$
}

where equality holds so long as the solution is interior with $0<\pi^{s *}<1$. Otherwise, when $\pi^{s *}=1$ we have $p_{H 2}^{s *}>p_{L 2}^{s *}$, and all of the banked permits go to the higher-priced region $H$. By assumption, we chose $H$ as the region that would have higher prices absent linking, so it is not possible that $\pi^{s *}=0$ and $p_{H 2}^{s *}<p_{L 2}^{s *}$.

${ }^{24}$ We previously suggested that New Jersey's exit from RGGI could be viewed as a case of symmetric delinking where $\pi=1$. However, one could also view it as a case of simpler symmetric delinking where permit holders also had a choice of using banked RGGI permits in New Jersey where the price would be zero. 
symmetric delinking. However, our interest in various delinking models is partly motivated by the idea that uncertainty or speculation about the delinking event could also raise costs. This makes delinking choices relevant not only when delinking becomes a serious consideration. Such choices are relevant even when regions intend their link to be permanent but the market doubts the regions' intentions.

As we explain in the following proposition, our previous results based on a certain delinking event require only minor modifications when a delinking event is uncertain (the proof is in Appendix A).

Proposition 3. Let $\phi$ be the subjective probability, as viewed by the market in period 1 , that the regions will be delinked in the second period. If the market assumes asymmetric delinking will occur, the first-order conditions in period one are given by those in (6) with prices $p_{r 2}^{a *}$ replaced by the expected prices $\mathbb{E}\left[p_{r 2}^{a *}\right]$. If the market assumes symmetric delinking will occur, the first-order conditions in period one are given by those in (8) with prices $p_{r 2}^{S *}$ replaced by the expected prices $\mathbb{E}\left[p_{r 2}^{S *}\right]$.

We see that uncertainty about delinking will lead to an outcome in the first period where expected second-period prices replace the previously certain delinked second-period prices, but otherwise the first-order conditions keep the same form. ${ }^{25}$ It is therefore straightforward to extend our previous analysis to allow for such uncertainty. Suppose for the moment that the market assumes asymmetric delinking will occur. Then abatement costs may be higher than first-best and first-period prices may diverge from one another. In contrast, an assumed policy of symmetric delinking will always maintain parity between the prices of each region's permits. Moreover, under the appropriate conditions, symmetric delinking obtains the first-best outcome for any value of $\phi$. This leads us to our final proposition, really a corollary of Proposition 2 (the proof is in Appendix A).

Corollary 1. Let $\phi$ be the subjective probability, as viewed by the market in period 1 , that markets are delinked in the second period. If (a) $w_{r 2}<e_{r 2}^{\ell *}$ for both regions, (b) the market assumes symmetric delinking will occur, and (c) the market assumes either $\pi=\frac{e_{H 2}^{t *}-w_{H 2}}{e_{H 2}^{t *}-w_{H 2}+e_{L 2}^{\epsilon *}-w_{L 2}}$ or that $\pi$ can be chosen by the market, then the first-best outcome is attained.

Thus we see that it is possible that uncertainty about delinking will not affect the market at all, thereby preserving the first-best outcome. This occurs if markets believe that banked permits will be treated symmetrically and that governments will either choose $\pi$ to seek to maintain prices, or let the market choose $\pi^{26}$

These results suggest that delinking policies matter, even if the regions have no intention of delinking. In this case speculation about delinking would be incorrect, but it may cause a deviation from the first-best outcome depending on the assumed policy regarding delinking. In particular, speculation about asymmetric delinking can lead prices to diverge and raise costs. Speculation about symmetric delinking can raise costs but never leads prices to diverge. Under the conditions of Corollary 1 , speculation about symmetric delinking would have no effect on the market.

\section{Numerical example: Australia and the European Union}

We conclude this section with a simple numerical example based on the 2012 proposal to link the European Union ETS with the emerging Australian trading system EC (2012). While the Australian program as well as the proposed link were repealed before the link became active (Innis, 2014), the repeal still serves to highlight our motivation: sovereign jurisdictions can change their minds about policies, and links between them are not immutable. It also allows us to see whether symmetric versus asymmetric delinking could matter in particular real-world situation, and perhaps gain intuition about the applicability of our results more generally. With that in mind, suppose the Australian trading program and proposed link to the EU-ETS had been implemented as planned. We are now in the year 2018 and the systems are fully linked. Some divergence of views emerge-over offsets, the appropriate permit price level, or some other design issue-and government officials are contemplating delinking the programs in 2020.

We parameterize the model so that period 1 can be thought of as the year 2019, when the programs are clearly linked, and period 2 can be thought of as 2020-2027, a later and 8 times larger period where they might or might not be linked. In a world where the systems remain linked, we imagine current and future permit prices $\left(p_{1}^{\ell *}=p_{2}^{\ell *}\right)$ equaling $\$ 15$ per ton. At $\$ 15$ per ton, equilibrium period 1 demand for permits is 300 million tons in Australia $\left(e_{A U, 1}^{\ell *}\right)$ and 1900 million tons in the EU $\left(e_{E U, 1}^{\ell *}\right)$; period 2 demand is 8 times period 1 demand (2400 and 15,200 million tons, respectively, for $e_{A U, 2}^{\ell *}$ and $e_{E U, 2}^{\ell *}$ ).

We assume an allocation that is 100 million tons short for Australia per year in both periods. This gives $w_{A U, 1}=300-100=200$ and $w_{A U, 2}=2400-8 \times 100=1600$. In general, the EU is therefore 100 million tons long per year, suggesting a net permit flow from the EU to Australia. This is what actual 2013 prices would have suggested. On top of this, we assume the EU starts with 1000 million tons extra in the first period (and period 2 is 1000 million tons short). This is consistent with the current, large EU bank, which the EU is attempting to correct by tightening future allocations. This amounts to $w_{E U, 1}=1900+100+1000=3000$ and $w_{E U, 2}=15,200+8 \times 100-1000=15,000$.

This arrangement matches Case 2 in our taxonomy of asymmetric delinking cases, where the maximum link constraint is binding, and symmetric delinking can reduce costs. To see this, note that (a) $w_{r 2}<e_{r 2}^{\ell *}$ in both regions, and (b)

\footnotetext{
${ }^{25}$ Once in the second period, emissions will be determined based on whether delinking occurs, as discussed in the Appendix proof.

${ }^{26}$ We must also have $w_{r 2}<e_{r 2}^{\ell *}$ for both regions, which implies banking must be part of the first-best equilibrium in both regions. Recall that most systems to date have set more ambitious future targets and accumulated large banks, consistent with this assumption.
} 
$w_{A U, 1}+w_{A U, 2}<e_{A U, 2}^{\ell *}$ (Australia is the high-price region). In other words, both regions are short in permits in period 2 relative to the fully linked equilibrium: Australia needs 2400 million permits in period 2 and the EU needs 15,200 million tons. But Australia's need is enormous, more than its total endowment over both periods. This is all fine when the programs are linked in period 2, but becomes a constraint with asymmetric delinking.

This example also provides more intuition about when the condition $w_{H 1}+w_{H 2}<e_{H 2}^{\ell *}$ might hold in practice. For example, if we assume $e_{\mathrm{H} 2}^{\ell *} \gg e_{\mathrm{H1}}^{\ell *}$ then we have $e_{\mathrm{H} 2}^{\ell_{*}^{*}}+e_{\mathrm{H1}}^{\ell *} \approx e_{\mathrm{H} 2}^{\ell *}$. This is consistent with the idea that the relevant future beyond a real or speculated delink would tend to be much larger than the time before it. If we further assume $e_{\mathrm{H} 1}^{\ell *}+e_{\mathrm{H} 2}^{\ell *} \gg w_{H 1}+w_{H 2}$, we then meet the Case 2 condition. This second assumption is implied if the high-price region is relatively small, a feature reflected in the two real-world scenarios we have seen to date: Both Quebec and Australia are small and have higher prices than their larger linking partners. ${ }^{27}$ This suggests that our focus on Case 2, and the idea that outcomes can be improved with symmetric versus asymmetric delinking, could be consistent with real-world conditions. Of course, the particular structure of supply and demand in a given situation will determine whether and by how much symmetric delinking matters.

To see what happens with asymmetric and symmetric delinking in our example, we need further assumptions about the elasticity of abatement supply. Here, we assume the abatement supply schedule in each region is defined by a constant elasticity of supply around the linked equilibrium described above,

$$
-C_{r t}^{\prime}=\$ 15\left(e_{r t} / e_{r t}^{\ell *}\right)^{-1 / \varepsilon_{r}},
$$

where $\varepsilon_{r}$ is the elasticity in region $r$. We calibrate $\varepsilon_{r}$ based on particular price assumptions. ${ }^{28}$

Table 1 shows the results for both asymmetric and symmetric delinking with various values of $\pi$. Here we report prices, banking, and the cost increase relative to the no-delinking scenario (expressed as a percentage of the roughly $\$ 8$ billion cost increase associated with complete delinking in both periods). As we would expect with Case 2, the asymmetric delinking solution results in high period 2 prices in Australia. Also notice the price dispersion in the first period. All of the first-period Australian permits are banked for use in the second period and first-period compliance in both regions is completely covered by EU permits. This raises costs relative to the no-delinking baseline, as shown in the last column.

Moving to symmetric delinking, we see that for any value of $\pi$ the first-period price dispersion is eliminated; all permits are treated and priced the same until the systems are delinked. Also notice that the variability over time and regions (in period 2) is reduced compared to the asymmetric case, so long as $\pi>0.2$. In these cases, symmetric delinking lowers cost as highlighted in the last column. For the value of $\pi=0.8$, which would also be the value chosen by the market under simpler symmetric delinking, the conditions of Proposition 2 are satisfied and the symmetric delinking outcome is first-best.

Next consider the effects of uncertainty about delinking. For symmetric delinking, with $\pi=0.8$, Corollary 1 implies that the first-best outcome is attained. This is not the case, of course, for asymmetric delinking or when $\pi \neq 0.8$, as shown in Table 2. When the probability of delinking is equal to zero, we obtain the first-best outcome for any policy (first row of Table 2). When the probability of delinking is equal to one (bottom row of Table 2), we obtain the same costs as the last column in Table 1. Intermediate values for $\phi$ lead to outcomes between the two extremes.

The results in Table 2 are based on expected second period costs. It is also of interest to consider actual period 2 costs, which will depend on whether or not delinking actually takes place. The outcome of remaining linked or delinking defines two cases given by Tables 3 and 4 (with Table 2 representing the average based on $\phi$ ). In the first case, Table 3, markets end up being linked in period 2. Regardless of their accuracy, market expectations about $\phi$ will govern behavior in the first period and determine banking levels. In period 2, the linked market will use the banked permits to reach an equilibrium. This cost calculation differs from Table 2, where second-period costs were an average of this outcome and the delinked equilibria with the probability of delinking equal to $\phi$. For example, the costs assuming extremely poor speculation $-E[\phi]=1$ when the programs remained linked-are given in the bottom row of Table 3. Results for other values of $E[\phi]$ when programs remain linked are given in other rows of Table 3.

While the cost increase from speculation appears low on a percentage basis, the dollar values in this example equal roughly $\$ 80$ million for each percentage point (e.g., "0.1" in the table equals $\$ 8$ million). This suggests a cost advantage of symmetric delinking relative to asymmetric delinking that could as large as $\$ 224$ million $(=8 \times 2.8$, when $E[\phi]=1)$. Moreover, these costs also do not include the added transaction costs we expect might arise under asymmetric delinking as 200 million EU allowances are acquired by Australians for compliance in 2019 because of the price divergence between the two permits. In this case, the cost advantage of symmetric versus asymmetric delinking does not arise from an actual delinking event-which governments may view as a negligible risk. Rather, it comes from avoiding damaging speculative behavior when markets are nonetheless worried about delinking and asymmetric treatment is assumed.

The second case of actual cost calculations occurs when markets are indeed delinked in period 2. Actual costs are determined by speculative behavior in period 1 , coupled with a resulting certain, delinked equilibrium in period 2 . The

\footnotetext{
${ }^{27}$ In order to meet the other condition of Case $2, e_{r 2}^{\ell *}>w_{r 2}$, we need the collective endowments to be relatively large in period 1 . Given the high-price region is small, that means there must be a large first-period endowment in the low-price region. In the case of the EU, there is currently a large bank equal to over a billion tons, matching our assumption. While it is too early to know whether there will be a similar bank in California, previous US programs have seen large banks, such as the acid rain trading program regulating $\mathrm{SO}_{2}$.

${ }^{28}$ We choose $\varepsilon_{r}$ such that the EU price equals $\$ 10$ and the Australian price quals $\$ 30$ when the 100 million trade balance each year is unsatisfied (e.g. when $e_{A U, 1}=e_{A U, 2} / 8=200$ and $e_{E U, 1}=e_{E U, 2} / 8=2000$ ). This leads to $\varepsilon_{A U}=0.585$ and $\varepsilon_{E U}=0.127$.
} 
Table 1

Australia and the EU: Symmetric and asymmetric delinking outcomes.

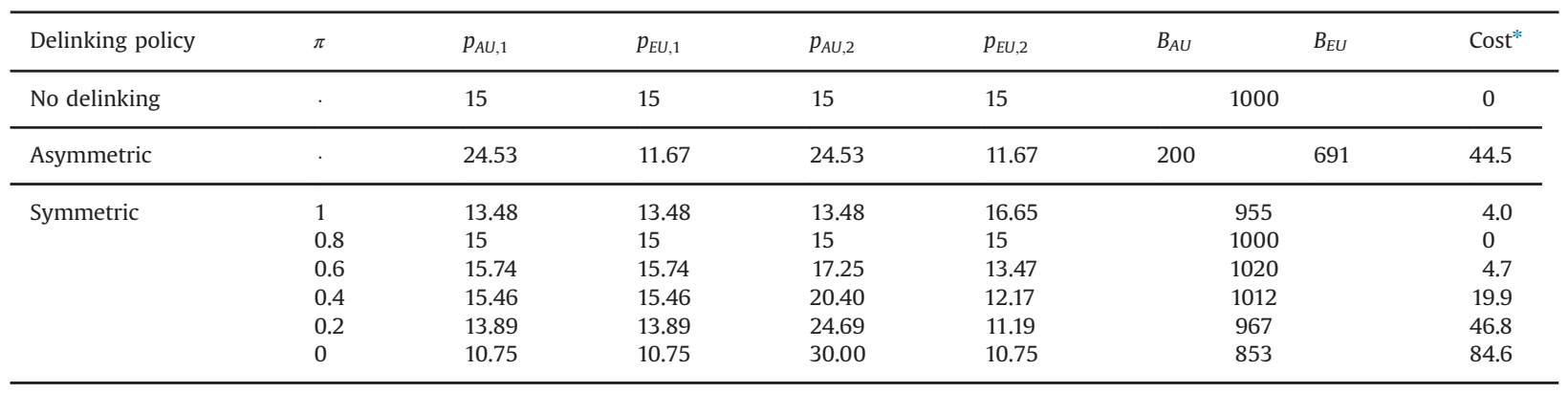

* The cost increase relative to the scenario with no delinking, expressed as a percent of the $\$ 8$ billion cost increase associated with delinking both periods.

Table 2

Australia and the EU: symmetric and asymmetric delinking costs with uncertainty $(\phi)$ about delinking (expressed as a \% of the $\$ 8$ billion cost increase from delinking both periods).

\begin{tabular}{|c|c|c|c|c|c|c|c|}
\hline \multirow[t]{3}{*}{$\phi$} & \multirow[t]{3}{*}{ Asymmetric } & \multicolumn{6}{|c|}{ Symmetric } \\
\hline & & \multicolumn{6}{|c|}{ Fraction of permits to EU $(\pi)$} \\
\hline & & 1 & 0.8 & 0.6 & 0.4 & 0.2 & 0 \\
\hline 0 & 0 & 0 & 0 & 0 & 0 & 0 & 0 \\
\hline 0.2 & 9.3 & 0.9 & 0 & 1.0 & 4.0 & 9.4 & 17.6 \\
\hline 0.4 & 18.4 & 1.7 & 0 & 1.9 & 8.0 & 18.8 & 34.9 \\
\hline 0.6 & 27.4 & 2.5 & 0 & 2.8 & 12.0 & 28.2 & 51.8 \\
\hline 0.8 & 36.0 & 3.3 & 0 & 3.8 & 15.9 & 37.5 & 68.4 \\
\hline 1 & 44.5 & 4.0 & 0 & 4.7 & 19.9 & 46.8 & 84.6 \\
\hline
\end{tabular}

Table 3

Australia and the EU: costs with speculation about delinking $(E[\phi] \geq 0)$ but delinking never happens $(\phi=0)$ (expressed as a \% of the $\$ 8$ billion cost increase from delinking both periods).

\begin{tabular}{|c|c|c|c|c|c|c|c|}
\hline \multirow[t]{3}{*}{$E[\phi]$} & \multirow[t]{3}{*}{ Asymmetric } & \multicolumn{6}{|c|}{ Symmetric } \\
\hline & & \multicolumn{6}{|c|}{ Fraction of permits to EU $(\pi)$} \\
\hline & & 1 & 0.8 & 0.6 & 0.4 & 0.2 & 0 \\
\hline 0 & 0 & 0 & 0 & 0 & 0 & 0 & 0 \\
\hline 0.2 & 0.1 & 0.0 & 0 & 0.0 & 0.0 & 0.0 & 0.2 \\
\hline 0.4 & 0.4 & 0.1 & 0 & 0.0 & 0.0 & 0.0 & 0.7 \\
\hline 0.6 & 0.9 & 0.2 & 0 & 0.0 & 0.0 & 0.1 & 1.6 \\
\hline 0.8 & 1.7 & 0.3 & 0 & 0.1 & 0.0 & 0.2 & 2.9 \\
\hline 1 & 2.8 & 0.5 & 0 & 0.1 & 0.0 & 0.3 & 4.8 \\
\hline
\end{tabular}

Table 4

Australia and the EU: costs with speculation about delinking $(E[\phi] \geq 0)$ and delinking does happen $(\phi=1)$ (expressed as a \% of the $\$ 8$ billion cost increase from delinking both periods).

\begin{tabular}{|c|c|c|c|c|c|c|c|}
\hline \multirow[t]{3}{*}{$E[\phi]$} & \multirow[t]{3}{*}{ Asymmetric } & \multicolumn{6}{|c|}{ Symmetric } \\
\hline & & \multicolumn{6}{|c|}{ Fraction of permits to EU $(\pi)$} \\
\hline & & 1 & 0.8 & 0.6 & 0.4 & 0.2 & 0 \\
\hline 0 & 68.1 & 4.5 & 0 & 4.8 & 19.9 & 47.1 & 88.9 \\
\hline 0.2 & 46.2 & 4.3 & 0 & 4.8 & 19.9 & 47.0 & 87.5 \\
\hline 0.4 & 45.5 & 4.2 & 0 & 4.7 & 19.9 & 46.9 & 86.3 \\
\hline 0.6 & 45.0 & 4.1 & 0 & 4.7 & 19.9 & 46.9 & 85.4 \\
\hline 0.8 & 44.6 & 4.0 & 0 & 4.7 & 19.9 & 46.9 & 84.8 \\
\hline 1 & 44.5 & 4.0 & 0 & 4.7 & 19.9 & 46.8 & 84.6 \\
\hline
\end{tabular}


results in this case are given in Table 4. Taken together, the results in Tables 3 and 4 provide a nice illustration of Corollary 1. Using symmetric delinking with a value of $\pi=0.8$ completely eliminates any consequences of speculation about delinking.

\section{Extension and discussion}

The main point of this paper has been to show that different delinking policies have important consequences for prices and abatement costs, and that these consequences arise even when mere speculation about delinking arises. We have not really had in mind an optimal delink policy from the standpoint of regions that really want to delink, in part because the objective in a delink policy is less clear than in a linking policy. In the case of a linking decision, cost-effectiveness is a key criterion, while in the case of a delinking decision, cost-effectiveness may be subservient to other considerations. In particular, the same reasons that drive the current system of independent and unlinked carbon-trading programs-a desire for different features, particularly different prices or levels of ambition-are likely to motivate delinking.

As we have seen, however, the decision to delink (or speculation about delinking) could lead current permit prices to diverge across regions before delinking occurs-perhaps long before-with potential increased transaction costs and political consequences from large permit flows. The divergence of prices across regions (and implicitly higher abatement costs) after delinking may be necessary for the reasons discussed above. The necessity of a price shift prior to delinking is less clear. However, the transaction costs associated with divergent regional permit prices before delinking are certainly not necessary. ${ }^{29}$

This suggests it may be useful to design a delinking policy that avoids price divergence prior to delinking but allows prices to diverge in the most flexible possible way after delinking. We call such a policy the "flexible" delinking policy. The key to this policy is to issue specific banking rights into each region rather than attaching them entirely to the current permits themselves. To date, the design of banking provisions has assumed that the holder of any current permit is free to hold that permit indefinitely for some future use rather than using it for compliance obligations now. Our previous discussions of symmetric and asymmetric treatment merely specified how that future use might be defined.

Suppose you instead needed an additional "banking right" to use a current permit in the future. Under the flexible delinking policy we issue $M_{H}$ rights to bank into region $H$ and $M_{L}$ rights to bank into region $L$-rights distinct from the emission permits themselves. To bank into region $r$ after delinking, a firm is required to hold one of these banking rights for region $r$ along with a period 1 permit from either region. So a region $r$ permit that is saved in period 1 may, depending on $M_{L}$ and $M_{H}$, be used for compliance in either region in period 2 (and a permit saved without holding a banking right will become worthless). In our mathematical representation of this delink policy, we need to distinguish between permits that are banked by region from period 1 , denoted by $B_{r 1}$, and permits that are banked by region into period 2 , denoted by $B_{r 2}$.

The market and implementation constraints for the flexible delinking policy can then be written as

$$
\begin{aligned}
& e_{H 1}=w_{H 1}+\Delta_{1}-B_{H 1} \\
& e_{L 1}=w_{L 1}-\Delta_{1}-B_{L 1} \\
& e_{H 2}=w_{H 2}+B_{H 2} \\
& e_{L 2}=w_{L 2}+B_{L 2} \\
& B_{H 2}+B_{L 2}=B_{H 1}+B_{L 1} \\
& B_{H 2} \leq M_{H} \\
& B_{L 2} \leq M_{L} \\
& B_{r 1} \geq 0 \\
& \Delta_{1} \leq e_{H 1}
\end{aligned}
$$

The corresponding first-order conditions are:

$$
\begin{aligned}
& \text { FOC for } e_{r t}:-C_{r t}^{\prime}=p_{r t}^{f *} \quad \text { (MAC equals price) } \\
& \text { FOC for } \Delta_{1}: p_{H 1}^{f *}=p_{L 1}^{f *} \equiv p_{1}^{f *} \quad \text { (Linking equates period 1 prices) } \\
& \text { FOC for } B_{r 1}: \lambda_{r}^{f *}=\lambda^{f *}=p_{1}^{f *}-p_{2, \text { base }}^{f *} \quad \text { (Rubin-Schennach banking equation) } \\
& \text { FOC for } B_{r 2}: p_{r 2}^{f *}=\mu_{r}^{f *}+p_{2, \text { base }}^{f *} \quad \text { (Flexible period } 2 \text { prices), }
\end{aligned}
$$

where the superscript $f^{*}$ indicates the solution to the flexible delinking problem, $p_{2 \text {,base }}$ is the Lagrange multiplier on the constraint equating total (across region) banking from period 1 with total (across region) banking into period 2, and $\mu_{r}^{f *}$ is the Lagrange multiplier on the banking limits established by $M_{r}$. As before $p_{r t}^{f *}$ are equilibrium permit prices in each period and region, and $\lambda_{r}^{f *}$ are the Lagrange multipliers on the no-borrowing constraints.

The flexible delinking policy is similar to the symmetric delinking policy in that there is no distinction between regional permits in period 1: they are both usable for compliance in each region and identically bankable. As before, this implies that

\footnotetext{
${ }^{29}$ As noted earlier, it seems the costs of such a large surge in transactions could be significant despite recent evidence that ordinary market transactions have quite low costs in key markets (Joas and Flachsland, 2014).
} 
the maximum link constraint is never binding and its Lagrange multiplier $\gamma^{f *}$ is equal to zero. ${ }^{30}$ Therefore, prices are equal in the first period.

But there is an important difference between the two policies. In the symmetric delink case, the fractional split of banked permits $\pi$ into region $H$ and $L$ determines one of the three prices ( $p_{1}^{S *}, p_{2 H}^{S *}, p_{2 L}^{S *}$ ) given the other two (based on the last FOC in (8)) when banking is active. In contrast, with the flexible delinking policy, $M_{L}$ and $M_{H}$ can be used to precisely control emissions and prices in both regions in period 2 . The Lagrange multipliers on the two associated constraints allow $p_{H 2}^{f *}$ and $p_{L 2}^{f *}$ to be the same or different from $p_{1}^{f *}$ in a flexible way (so long as $p_{r 2}^{f *} \geq p_{1}^{f *}$ ). Higher period 2 prices in either region can be achieved by reducing the relevant $M_{r}$. Lower period 2 prices in either region can be achieve by raising the relevant $M_{r}$, but only up to the point where prices are equalized with period 1 . At that point, the constraint will become slack and it is impossible to shift any more permits into that region.

The flexible delinking policy is more complex than the previous ones and requires additional decisions about the level and allocation of banking rights. We do not analyze these decisions here, rather we merely point out that cost-effectiveness cannot determine $M_{r}$ or they would be non-binding. But this policy does avoid price dispersion before delinking and allows prices before and after delinking to be manipulated in the most flexible possible way. Moreover, these decisions are not ones that are necessary before delinking is contemplated. Flexible delinking is entirely consistent with the general notion that all permits be treated the same, regardless of origin.

Turning now to other issues, we have implicitly assumed that there are two distinct permit denominations, one for each region. Alternatively, it is possible to link to regions in such a way that there is a single permit denomination, reducing the potential for delinking to discriminate between permits. For example, unlike RGGI, the shared registry for California and Quebec does not indicate the jurisdiction of origin, suggesting a single linked denomination. ${ }^{31}$ With a single denomination, the potential for asymmetric delinking is removed, and the only question is whether and where to fix $\pi$. If the regulatory agencies do not make an explicit announcement about $\pi$, then they will, by default, be implementing the simpler symmetric delinking, as the market will make this choice for them.

An obvious limitation of our approach is that it takes future permit endowments as fixed across various linking and delinking scenarios. Regions clearly have the ability to change future endowment along with linking rules. Moreover, we have not modeled the events that might lead one or both regions to consider delinking or how the delinking decision might be executed. For example, regions might be interested in triggers that would halt trading on the basis of unusual permit flows. Such flows might represent the onslaught of speculation about delinking, or could signal a failure to maintain one program's integrity (perhaps through some kind of fraudulent creation of permits). An automatic halt in trading could give authorities time to diagnose the problem and decide what to do-including a possible delink-before trading potentially expands the scope of such a problem. This might be somewhat analogous to the automatic rules for halting trades on stock exchanges in the face of large price swings. None of these issues, however, change the basic result that asymmetric treatment can cause prices to diverge prior to delinking, even based on speculation, while symmetric treatment avoids price divergence.

A final issue is whether and how any discussion of delinking possibilities might encourage speculation that it will occur. That is, does a decision to include an explicit delinking provision in the initial linking agreement provision raise expectations of delinking ${ }^{32}$ In the absence of a formal delinking provision, asymmetric delinking is perhaps the most plausible outcome in the event that delinking does indeed occur. Thus our results suggest an important trade-off exists for jurisdictions contemplating a link: ignore the possibility of delinking and perhaps communicate a greater commitment to a permanent link-but also risk that a future decision to delink, or mere speculation about such a decision, could be disruptive to market prices and raise costs. Or, plan for delinking-which might be as simple as stipulating that future policy changes will always treat permits in public circulation identically, regardless of origin. Such an exercise might create more uncertainty about the durability of the link, but could ensure that any future delinking event, or speculation about such an event, would be less disruptive and less costly. ${ }^{33}$

\footnotetext{
${ }^{30}$ If $\gamma^{f *}>0$, then $p_{H 1}^{f *}$ would be replaced by $p_{H 1}^{f *}-\gamma^{f *}$ in the FOCs for $e_{H 1}$ and $\Delta_{1}$ and we know that $e_{H 1}^{f *}=\Delta_{1}^{f *}$. This implies $B_{H 1}^{f *}=w_{H 1}>0$ and $\lambda_{H}=0$. In turn, $p_{H 1}^{f *}=p_{2 \text {,base }}^{f *}$ while $p_{L 1}^{f *}=p_{2, \text { base }}^{f *}+\lambda_{L}^{f *} \geq p_{2 \text {,base }}^{f *}=p_{H 1}^{f *}$. But this contradicts $p_{L 1}^{f *}=p_{H 1}^{f *}-\gamma^{f *}<p_{H 1}^{f *}$ implied by $\gamma^{f *}>0$. Therefore, $\gamma^{f *} \ngtr 0$.

31 In this case at least, the jurisdictions should know the origin based on serial numbers; it is also possible permit buyers and sellers (who cannot see the serial number) might try to deduce the origin based on vintage and owner. In the California and Quebec systems, it is also the case that permit holders are registered in one jurisdiction or another, creating the possibility that banked permits could be differentiated based on ownership after a delink. The practicality and legality of asymmetric treatment in this context are unclear.

32 This is analogous to the perception that a prenuptial agreement prior to marriage signals uncertainty about marriage. See Mahar (2003).

${ }^{33}$ We can illustrate this trade-off in our numerical example. Suppose there is no chance of delinking (for the foreseeable future, at least), but the market believes otherwise as assumed in Table 3. With no explicit delinking provision, the market assumes asymmetric delinking and speculates that $E[\phi]=0.2$. Based on Table 3, the cost of this speculation is $0.1 \%$ (second row of Asymmetric column). If the government makes an announcement that future policy changes will treat permits identically, imagine this raises market speculation to $E[\phi]=0.4$. Based on values in the third row of Table 3 , the cost of this outcome is less than $0.1 \%$ so long as $0.2 \leq \pi \leq 0.8$. This would not be a bad trade-off. But if the announcement raised $E[\phi]$ to 0.6 , and the market believed $\pi=1$, costs would be twice as large as for $E[\phi]=0.4$. All of this suggests that more open discussion and analysis of the effects of policy choice on market perceptions are likely warranted.
} 


\section{Conclusions}

Once two jurisdictions decide to create a compliance link between their emission trading programs, policymakers must decide whether, when, and how to address the possibility of delinking. This paper demonstrates that the choice of how delinking occurs-particularly whether banked permits are treated symmetrically or asymmetrically-has important consequences for abatement costs and whether prices will diverge between regions in advance of a delinking event. In particular, delinking often leads to rising abatement costs. But the number of cases in which abatement costs increase, and the magnitude of these increases, can be reduced by using symmetric treatment of banked permits rather than asymmetric treatment. In addition, symmetric treatment prevents price divergence prior to delinking. Most importantly, these results hold regardless of whether the delinking event is real or speculative, emphasizing the need to at least contemplate this issue well before delinking is a serious concern.

Whether and by how these choices about delinking affect actual costs in a given context will depend on the structure of supply and demand in that context. However, in our numerical example, we see that both the Australia-EU and QuebecCalifornia links have the key ingredients for a difference to arise: They both involve a large market linking to a much smaller market with a higher price. Our effort to parameterize the Australize-EU link in more detail further suggests the costs could be significant.

While the main motivation for this paper was to show that delinking policies ought to be contemplated when a compliance link is initially established, we also discussed the broader context of delinking decisions. A delinking policy could be more flexible than our initial models in order to achieve a broader set of outcomes. It would also be useful to consider how a delinking decision might emerge as a real-time response to changing circumstances. And finally, we note that the act of making a public decision about how delinking would occur-even in the absence of an intention to delink and distinct from the particulars of the decision itself-may influence market perceptions of the likelihood of delinking.

More generally, this paper points to an underappreciated feature of tradable permit policies: Market participants can speculate about policy changes in ways that compromise the cost-effectiveness (and possibly other desirable elements) of the policy. ${ }^{34}$ This may be a necessary consequence of a real policy change-or it may be a needless cost if the speculation is unfounded (or the change is poorly managed). Thinking about one particular policy change-the termination of a compliance link-we have focused on design choices that could minimize unnecessary costs. However, this recognition may also have consequences for how we view the relative advantage of tradable permits compared to other policies such as taxes and traditional regulation.

\section{Acknowledgments}

Useful comments on earlier drafts were provided by workshop participants at the AERE Summer Meetings in Banff, the Sanford Seminar Series at Duke University, the Regulatory Policy Program at Harvard Kennedy School, Cambridge University, the London School of Economics, Yale University, two anonymous referees and the editor, Till Requate. We thank John Agan and Rob Stavins for useful conversations about termination provisions in existing linking agreements, and Carl Yin for research assistance with an early version of this work.

\section{Appendix A}

Proof of Proposition 3. When there is uncertainty about delinking in the second period, we use a dynamic optimization problem to characterize the market equilibrium rather than a static optimization problem. Following Samuelson (1971), we know that a rational expectations market equilibrium, in which competitive storage firms determine the permit banking decisions, will be equivalent to the solution to a stochastic dynamic programming problem. So we use this dynamic program to characterize emissions and prices in our model. As is standard, we solve it backward, starting from the second period.

We characterize the second-period solutions by defining a value function for each possible outcome in terms of the banking level in each region. In particular, for the event that the systems remained linked we define,

$$
V_{2}^{\ell}\left(B_{H}, B_{L}\right)=\min _{e_{H 2}, e_{L 2}, \Delta_{2}} C_{H 2}\left(e_{H 2}\right)+C_{L 2}\left(e_{L 2}\right)
$$

such that

$$
\begin{aligned}
& e_{H 2}=\Delta_{2}+w_{H 2}+B_{H} \\
& e_{L 2}=-\Delta_{2}+w_{L 2}+B_{L} .
\end{aligned}
$$

\footnotetext{
${ }^{34}$ In a model with signaling, Harstad and Eskeland (2010) make a related point about the effect of changes in the way in which permits are allocated among firms. Koch et al. (2014) present evidence that market participants ignore policy announcements that should indicate higher future permit prices.
} 
For the event that the systems face an asymmetric delink we define,

$$
V_{2}^{a}\left(B_{H}, B_{L}\right)=\min _{e_{H 2}, e_{L 2}} C_{H 2}\left(e_{H 2}\right)+C_{L 2}\left(e_{L 2}\right)
$$

such that

$$
\begin{gathered}
e_{H 2}=w_{H 2}+B_{H} \\
e_{L 2}=w_{L 2}+B_{L} .
\end{gathered}
$$

And, for the event that the systems face a symmetric delink we define,

$$
V_{2}^{s}\left(B_{H}, B_{L}\right)=\min _{e_{H 2}, e_{L 2}} C_{H 2}\left(e_{H 2}\right)+C_{L 2}\left(e_{L 2}\right)
$$

such that

$$
\begin{aligned}
& e_{H 2}=w_{H 2}+\pi\left(B_{H}-B_{L}\right) \\
& e_{L 2}=w_{L 2}+(1-\pi)\left(B_{H}+B_{L}\right) .
\end{aligned}
$$

Let $\mathbb{E}\left[V\left(B_{L}, B_{H}\right)\right]=\phi V^{d}\left(B_{L}, B_{H}\right)+(1-\phi) V^{\ell}\left(B_{L}, B_{H}\right)$ and $d \in\{a, s\}$ depending on whether asymmetric or symmetric delinking is assumed. Note that

$$
\begin{aligned}
\frac{\partial \mathbb{E}[V]}{\partial B_{r}} & =\phi \frac{\partial V^{d}}{\partial B_{r}}+(1-\phi) \frac{\partial V^{\ell}}{\partial B_{r}} \\
\frac{\partial V^{a}}{\partial B_{r}} & =p_{r 2}^{a} \\
\frac{\partial V^{s}}{\partial B_{r}} & =\pi p_{H 2}^{s}+(1-\pi) p_{L 2}^{s} \\
\frac{\partial V^{\ell}}{\partial B_{r}} & =p_{r 2}^{\ell}=p_{2}^{\ell}=\pi p_{2}^{\ell}+(1-\pi) p_{2}
\end{aligned}
$$

where, as before, $p_{r 2}$ are the Lagrange multipliers on the permit market constraints in period 2 with superscript indicating the linking or delinking policy. The last result also makes use of the first-order condition for $\Delta_{2}$ that implies $p_{H 2}^{\ell}=p_{L 2}^{\ell}$.

From these, we can see that

$$
\frac{\partial \mathbb{E}[V]}{\partial B_{r}}=\phi p_{r 2}^{a}+(1-\phi) p_{r 2}^{\ell}=\mathbb{E}\left[p_{r 2}\right]
$$

when asymmetric delinking is assumed and

$$
\frac{\partial \mathbb{E}[V]}{\partial B_{r}}=\pi \mathbb{E}\left[p_{H 2}\right]+(1-\pi) \mathbb{E}\left[p_{L 2}\right]
$$

when symmetric delinking is assumed.

The first-period problem is

$$
\min _{e_{r 1}, B_{r}} C_{H 1}\left(e_{H 1}\right)+C_{L 1}\left(e_{L 1}\right)+\mathbb{E}\left[V\left(B_{L}, B_{H}\right)\right]
$$

such that

$$
\begin{aligned}
& e_{H 1}=\Delta_{1}-B_{H}+w_{H 1} \\
& e_{L 1}=-\Delta_{1}-B_{L}+w_{L 1} \\
& -B_{r} \leq 0 \\
& \Delta_{1}-e_{H 1} \leq 0,
\end{aligned}
$$

where the last constraint can be ignored without loss of generality with symmetric delinking.

With asymmetric delinking, the first-order conditions are

FOC for $e_{L 1}:-C_{L 1}^{\prime}=p_{L 1}^{a *} \quad$ (MAC equals price except maybe $H 1$ )

FOC for $e_{H 1}:-C_{H 1}^{\prime}=p_{H 1}^{a *}-\gamma^{a *}$

FOC for $\Delta_{1}: p_{H 1}^{a *}-\gamma^{a *}=p_{L 1}^{a *} \quad$ (Linking equates $H$ and $L$ MAC in period 1 but perhaps not prices)

FOC for $B_{r}: \lambda_{r}^{a *}=p_{r 1}^{a *}-\mathbb{E}\left[p_{r 2}^{a *}\right] \quad$ (Rubin - Schennach banking equation)

And, with symmetric delinking, the first-order conditions are

FOC for $e_{r 1}:-C_{r 1}^{\prime}=p_{r 1}^{s *} \quad$ (MAC equals price)

FOC for $\Delta_{1}: p_{H 1}^{s *}=p_{L 1}^{s *}=p_{1}^{s *} \quad$ (Linking equates $H$ and $L$ prices in period1)

FOC for $B_{r}: \lambda_{r}^{s *}=p_{r 1}^{S *}-\pi \mathbb{E}\left[p_{H 2}^{s *}\right]-(1-\pi) \mathbb{E}\left[p_{L 2}^{s *}\right]=\lambda^{S *} \quad$ (Banking under symmetric delinking) 
口

Proof of Corollary 1. Suppose at first the value of $\pi$ is as specified in the corollary. The first-best solution $e_{r t}^{\ell *}, \Delta_{t}^{\ell *}$, and $B_{r}^{\ell *}$ is feasible for the dynamic problem with uncertainty. (The first period constraints and the constraints when the systems remained linked in the second period are trivially satisfied. The arguments in the proof of Proposition 2 show the constraints when the systems are symmetrically delinked in the second period are satisfied.) This solution must be in fact optimal, for if it were not, then there would exist a solution that gave lower costs than first-best when markets were either linked or delinked, or in both cases.

If instead the value of $\pi$ is determined by the market, it must lead to costs at least as low as those for the value of $\pi$ specified in the corollary; therefore we obtain the optimal solution in this case as well.

\section{Appendix B. Relaxing the no borrowing constraint}

It is useful to consider how generalizing the no borrowing constraint affects our main results in Proposition 2, given that some programs include borrowing provisions. First, it is always possible to transform the mathematical problem to eliminate borrowing: Redefine the first period endowments to include the borrowing limit and the second period endowments to remove it (e.g., $w_{r 1}^{\prime}=w_{r 1}+\bar{B}_{r}$ and $w_{r 2}^{\prime}=w_{r 2}-\bar{B}_{r}$ ), and solve the problem with $-B_{r}^{\prime} \leq 0$. This primed version of the problem without borrowing delivers the same outcomes as the original problem with borrowing. Whether this is applicable in reality depends on how the delinking rules treat "borrowed" permits. In particular, would the symmetric delinking rules define a region $r^{\prime}$ s bank as "all the region $r$ permits that could be used in period 1, but were not used," (e.g., $\left.B_{r}^{\prime}=w_{1 r}^{\prime}-e_{1 r}=w_{1 r}+\bar{B}_{r}-e_{1 r}\right)$. If so, the real problem matches the transformed mathematical problem and the original results hold once again. ${ }^{35}$

If symmetric borrowing does not define the bank in terms of the permits that could be used in period 1, the real problem does not match this transformed mathematical problem. Moreover, we have to consider how symmetric banking works with a negative bank. A natural candidate is to define the volume going to region $H$ as

$$
\pi\left(\max \left\{B_{H}, 0\right\}+\max \left\{B_{L}, 0\right\}\right)+\min \left\{B_{H}, 0\right\}
$$

(and similarly for region $L$ ). That is, any positive banking would be shared, but borrowing would continue to count against the region of origin. In this case, our original results continue to hold in a generalized way. If the first-best solution does not involve borrowing, symmetric banking can achieve that outcome using $\pi$ as defined in Proposition 2 . If not, symmetric banking can do at least as well asymmetric banking because there is a value of $\pi$ that can replicate that outcome (either as defined in Proposition 2, or as $\pi=1$ or $\pi=0$ if banking occurs in only one region).

Thus our general result that symmetric delinking offers a potential improvement-and no loss-over asymmetric delinking continues to hold.

\section{References}

Arvanitakis, A., 2014. EU ETS: Is the Market Stability Reserve the Right Tool for Remedying Oversupply? Fridtjof Nansen Institute, Oslo. 〈http://www.fni.no/ doc\&pdf/FNI-Climate-Policy-Perspectives-12.pdf $\rangle$.

Combet, Greg, 2012. Transcript of Press Conference on Linking with the EU Emissions Trading System, 28 August, Australian Government, Department of Industry, Innovation, Climate Change, Science, Research and Tertiary Education, Canberra. 〈http://www.climatechange.gov.au/ministers/hon-greg-com bet-am-mp/transcript/transcript-press-conference-linking-eu-emissions-trading $\rangle$.

Cronshaw, M., Kruse, J., 1996. Regulated firms in pollution permit markets with banking. J. Regul. Econ. 9, 179-189.

EC (European Commission), 2012. Australia and European Commission Agree on Pathway Towards Fully Linking Emissions Trading Systems, Press Release, 28 August. 〈http://ec.europa.eu/clima/news/articles/news_2012082801_en.htm〉.

Flachsland, C., Marschinski, R., Edenhofer, O., 2009. To link or not to link: benefits and disadvantages of linking cap-and-trade systems. Clim. Policy 9 , $358-372$.

Innis, M., 2014. Australia Scraps Tax on Carbon, July 17, New York Times, p. A7.

Jaffe, J., Ranson, M., Stavins, R., 2009. Linking tradable permit systems: a key element of emerging international climate change policy. Ecol. Law Q. 36 789-808.

Joas, F., Flachsland, C., 2015. The (ir)relevance of transaction costs in climate policy instrument choice: an analysis of the EU and the US. Clim. Policy, http:/ dx.doi.org/10.1080/14693062.2014.968762 in press.

Jotzo, F., Betz, R., 2009. Australia's emissions trading scheme: opportunities and obstacles for linking. Clim. Policy 9, 402-414.

Koch, N., Fuss, S., Grosjean, G., Edenhofer, O., 2014. Causes of the EU ETS price drop: recession, CDM, renewable policies or a bit of everything?. Energy Policy 73, 676-685.

Haites, E., 2009. Linking emissions trading schemes for international aviation and shipping emissions. Clim. Policy 9, 415-430.

Haites, E., Mehling, M., 2009. Linking existing and proposed GHG emissions schemes in North America. Clim. Policy 9, $373-388$.

Harstad, B., Eskeland, G., 2010. Trading for the future: signaling in permit markets. J. Public Econ. 94, 749-760.

Helm, C., 2003. International emissions trading with endogenous allowance choices. J. Public Econ. 87, $2737-2747$.

Hufbauer, G., Schott, J., 2005. In: NAFTA Revisited: Achievements and ChallengesInstitute for International Economics, Washington.

Mahar, H., 2003. Why Are There So Few Prenuptial Agreements? Harvard Law School John M. Olin Center for Law, Economics and Business Discussion Paper series. Paper 436. 〈http://Isr.nellco.org/harvard_olin/436〉.

${ }^{35}$ When New Jersey exited the RGGI program, circulating future vintage New Jersey permits were brought into the remaining RGGI program, suggesting this might be the case. 
Mehling, M., Haites, E., 2009. Mechanisms for linking emissions trading schemes. Clim. Policy 9, 169-184.

Ranson, M., Stavins, R., 2013. Linkage of Greenhouse Gas Emissions Trading Systems: Learning from Experience, Discussion Paper ES 2013-2, Cambridge, Mass: Harvard Project on Climate Agreements, November 2013.

Rubin, J.D., 1996. A Model of intertemporal emission trading, banking, and borrowing. J. Environ. Econ. Manag. 31 (3), $269-286$.

Samuelson, P., 1971. Stochastic speculative price. Proc. Natl. Acad. Sci. 68, 335-337.

Schennach, S., 2000. The economics of pollution permit banking in the context of Title IV of the 1990 Clean Air Act Amendments. J. Environ. Econ. Manag. 40 (3), 189-210.

Sterk, W., Kruger, J., 2009. Establishing a transatlantic carbon market. Clim. Policy 9, 389-401.

Tuerk, A., Mehling, M., Flachsland, C., Sterk, W., 2009. Linking carbon markets: concepts, case studies and pathways. Clim. Policy 9, $341-357$. 